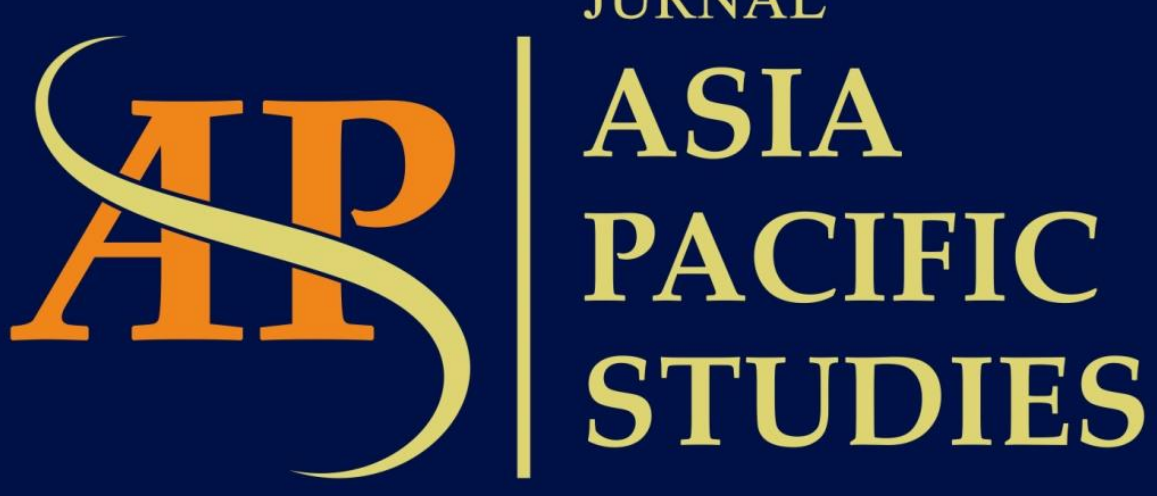

Journal of International Relations Study Program Faculty of Social and Political Sciences Universitas Kristen Indonesia 


\title{
PERSAINGAN CHINA-AUSTRALIA DALAM PEREBUTAN PENGARUH DI KAWASAN PASIFIK
}

\author{
Siti Nadjiha \\ Program Studi Ilmu Hubungan Internasional, Fakultas Ilmu Sosial dan Politik, \\ Universitas Islam Negeri Syarif Hidayatullah Jakarta, Jl. Ir H. Juanda, Kota Tangerang Selatan, 15412 \\ snadjiha@gmail.com
}

\begin{abstract}
The rise of China in the Pacific region is a threat to Australia as a traditional actor who has an important influence and role in the region. The rise of China pushed Australia to increase its role in the region. The Australian Government responded by channeling funds to Pacific countries to build infrastructure, a step taken by the Australian government is considered to counteract China's influence in the Pacific. With a series of major investment funds and development assistance projects, Australia and China are trying to compete with each other to create a network of their power and influence in the Pacific countries. This journal discusses the role of China-Australia in the competition for influence in the Pacific Region, using qualitative methods aimed at describing and analyzing a phenomenon systematically. This method will explain how China's role in the Pacific region increases and Australia's response as one of the traditional actors in the region. The discussion in this journal is the influence of Australia in the Pacific, the increasing role of China and Australia's response to China's rise in the Pacific Region.
\end{abstract}

Keywords: Australia, China, Pacific Islands

\begin{abstract}
Abstrak
Kebangkitan China di kawasan Pasifik menjadi ancaman tersendiri bagi Australia sebagai aktor tradisional yang memiliki pengaruh dan peran penting dikawasan. Kebangkitan China mendorong Australia untuk meningkatkan kembali perannya dikawasan. Pemerintah Australia merespon dengan akan menyalurkan dana ke negara-negara Pasifik untuk membangun infrastruktur, langkah yang diambil oleh pemerintah Australia ini dinilai untuk menangkal pengaruh China di Pasifik. Dengan serangkaian dana investasi utama dan proyek-proyek bantuan pembangunan, Australia dan Cina berusaha saling berlomba-lomba untuk menciptakan jaringan kekuasaan dan pengaruh mereka di negara-negara Pasifik. Jurnal ini membahas tentang Peran China-Australia dalam Persaingan pengaruh di Kawasan Pasifik, dengan mengunakan metode kualitatif yang bertujuan menggambarkan dan menganalisa suatu fenomena secara sistematis. Metode ini akan menjelaskan bagaimana peningkatan peran China dikawasan Pasifik serta respon Australia sebagai salah satu aktor tradisional di kawasan. Adapun pembahasan dalam jurnal ini yaitu pengaruh Australia di Pasifik, peningkatan peran China serta respon Australia terhadap kebangkitan China di Kawasan Pasifik.
\end{abstract}

Kata kunci: Australia, China, Kepulauan Pasik 


\section{Pendahuluan}

\subsection{Latar Belakang}

Kepulauan Pasifik merupakan kepulauan yang sebagian besar dihuni oleh negaranegara dengan luas wilayah dan populasi yang kecil, pertumbuhan ekonomi yang lemah, infrastruktur primitif, layanan pemerintah yang kurang baik serta tidak stabil secara politik. Meskipun demikian, negara-negara di Kepulauan Pasifik memiliki potensi ekonomi yang cukup menjanjikan. Pulau-pulau di Samudra Pasifik dibagi menjadi tiga dengan masyarakat budaya Polinesia, Melanesia, dan Mikronesia. Ketiganya mempunyai berbagai macam perbedaan baik secara historis berdasarkan geografi, bahasa, budaya, maupun karakter fisik (Brown 2012). Negara-negara dalam kepulauan ini banyak diwarnai dengan berbagai macam konflik, baik itu konflik ras, kudeta dan terdapat beberapa negara yang masih lemah dalam hal penegakan hukum. Selain itu, tingginya ancaman kriminalitas transnasional yang terjadi, seperti perdagangan narkoba dan manusia, terorisme, sengketa laut, kejahatan dunia maya, ekstrimisme dan sebagainya.

Australia sebagai pemain tradisional dikawasan merupakan negara yang memiliki pengaruh serta kekuatan besar di kawasan ini. Australia telah lama tecatat sebagai mitra dagang serta pendonor bantuan terbesar khususnya di Pasifik Selatan. Sebagai negara terkaya di Oseania secara geografis Australia merupakan negara yang berdekatan dengan negaranegara Pasifik sehingga Australia memiliki kedekatan bilateral yang cukup besar di Pasifik. Hal itu meningkatakan peran Australia sebagai negara pemberi bantuan dana di negara-negara Pasifik (Allan, Gyngell \& Wesley 2003). Sebagian besar negara di Pasifik sangat bergantung terhadap bantuan Australia dan Selandia Baru, terutama melalui Pasifik Forum. Adapun ketergantungan terhadap bantuan asing ini terjadi akibat kecilnya jumlah populasi mereka, yang menjadikan peran mereka dalam pepolitikan dan perdagangan global sangat kecil (Leppman, Elizabeth 2006).

Salah satu tujuan Australia yakni sebagai upaya untuk mencegah destabilisasi yang dapat mendorong terjadinya kejahatan internasional. Sebagai pemain utama yang juga memiliki berbagai kepentingan, Australia sangat memperhatikan keamanan kawasan tersebut. Australia juga telah berperan secara aktif membantu menyebarkan nilai nilai good governance dan national building di kawasan Pasifik. Serta terlibat dalam upaya menjaga perdamaian di kawasan Pasifik Selatan. Kepentingan Australia ini dianggap sangat berpengaruh di kawasan Pasifik Selatan. Sebagai sekutu utamanya Amerika Serikat mengakui bahwa Australia merupakan negara yang berpengaruh di Pasifik Selatan. Di samping itu, AS juga mengakui bahwa Australia memiliki tanggung jawab di wilayah ini (Brown 2012)

Kebangkitan China di Pasifik yang disebabkan oleh pertumbuhan ekonomi yang melesat menjadikan China sebagai salah satu negara dengan kekuatan ekonomi terbesar didunia. Kehadiran China di Pasifik yang ditandai dengan adanya investasi terhadap negaranegara di Pasifik serta bantuan dalam jumlah besar. Hal ini menjadikan China tercatat sebagai negara pendonor terbesar setelah Australia dan AS. Dalam melebarkan pengaruhnya China juga melakukan diplomasi kultural, seperti membangun sekolah hukum di University of the South Pacific di ibu kota Fiji yakni Suva, melakukan pertukaran pelajar, serta mengadakan pengajaran Bahasa Mandarin didalam stasiun televisi lokal.

Meningkatnya pengaruh China di Pasifik ditinjau dari serangkaian bantuan luar negeri yang signifikan yang diberikan oleh China terhadap negara-negara dikawasan yang memiliki hubungan diplomatik dengannya. Hal ini dilakukan China sebagai upaya untuk memperkuat perdagangan, meningkatkan pembangunan infrastruktur, kemampuan pemerintah dan militer, serta upaya untuk mengembangkan sumber daya alam (Shie 2010). Dengan adanya berbagai bantuan ekonomi yang diberikan China dengan tidak mengikat serta bersyarat lunak (Yang 
2009), bantuan ini menjadi daya tarik tersendiri bagi negara-negara di kawasan yang sebagian besar memiliki penghasilan nasional di bawah rata-rata. Pengaruh China inilah yang membuat China dijuluki sebagai banker baru di kawasan.

Adapun Kebangkitan China di kawasan Pasifik yang semakin meningkat dan intensif memicu berbagai kekhawatiran serta dianggap sebagai ancaman khususnya bagi para pemain tradisional dikawasan yang dapat tergeser oleh China, seperti Amerika Serikat, Australia dan Selandia Baru. Sebagai pemain lama dikawasan, Amerika Serikat mendorong sekutunya yang juga memiliki pengaruh besar dikawasan ini yakni Australia untuk meningkatkan perannya kembali upaya menangkal pengaruh China yang semakin besar dikawasan. Tidak hanya oleh pemain tradisional, kehadiran China memicu berbagai respon, dari yang optimis seperti kekaguman sampai yang pesimis, seperti kecemburuan, kewapadaan, kecurigaan, penolakan, (Bustelo 2005).

Wilayah Pasifik merupakan wilayah yang strategis sehingga memicu adanya persaingan pengaruh untuk melancarkan kepentingan keamanan dan ekonomi masing-masing negara (Putri 2019). Australia dan China berupaya saling berlomba-lomba untuk melebarkan pengaruhnya dengan menciptakan jaringan kekuasaan di negara-negara Pasifik. Oleh karena itu, penulis tertarik untuk membahas mengenai Persaingan China-Australia dalam Peningkatan Peran di Kawasan Pasifik. Untuk mengetahui pengaruh Australia sebagai aktor tradisional dikawasan dan melihat peningkatan peran serta kepentingan China dikawasan, dan respon Pemerintah Australia terhadap kebangkitan China.

\section{Metode Penelitian}

Penulisan dalam jurnal ini menggunakan pendekatan kualitatif. yaitu dengan cara mengumpukan data yang berupa kata-kata, gambar dan bukan angka-angka (Danim 2002). Dalam penelitian kualitatif ini dilakukan dengan tidak menggunakan proses kuantifikasi data baik dalam proses pengumpulan dan analisis data. Menurut Alan Bryman (2004: 366), untuk menjelaskan keterkaitan suatu hal, penelitian dengan menggunakan metode kualitatif tidak dilakukan dengan cara menghitung ataupun mengukur data statistik akan tetapi dalam penelitian ini lebih berfokus pada pemaknaan dalam bentuk narasi agar dapat memperoleh gambaran atau penjelasan terhadap kasus yang menjadi fokus penelitian. Dalam metode kualitatif penjelasan dilakukan secara detail agar dapat menginformasikan secara jelas apa yang menjadi fokus dalam penelitian.

Melalui metodologi ini, peneliti dapat mengelaborasi berbagai macam data untuk dapat menjelaskan persaingan yang terjadi antara China dan Australia dalam perebutan pengaruh di Pasifik. Penelitian ini disajikan berupa narasi sebagai upaya menganalisis persaingan antara kedua negara, serta untuk menjawab rumusan masalah yang ada. Sedangkan teknik pengumpulan data dalam penelitian ini dilakukan dengan studi pustaka, yang bertujuan untuk mengumpulkan informasi yang relevan dengan topik yang menjadi objek penelitian. Adapun teknik analisis data dilakukan dengan reduksi data yakni mencari dan memilah data yang dianggap sesuai dengan topik penelitian ini, kemudian ditopang dengan teori dasar yang relevan dengan masalah yang akan diteliti, serta dilakukan penyajian data yaitu dengan menampilkan narasi dengan jelas dan terakhir menarik kesimpulan.

\section{Landasan Teori}

Adapun teori yang digunakan dalam jurnal ini yakni national interest atau kepentingan nasional. Kepentingan nasional merupakan sebuah landasan atau dasar dari pembuatan kebijakan luar negeri suatu negara. Dalam hal ini kepentingan nasional dapat 
diartikan sebagai suatu instrumen negara guna mencapai keinginannya. Kepentingan nasional suatu negara juga bertujuan untuk dapat melindungi masyarakatnya dan melindungi wilayahnya. Seperti dalam pandangan salah satu filsuf Inggris terkenal yakni Thomas Hobbes yang berpandangan bahwa setiap negara memiliki peranannya masing-masing agar dapat bertanggung jawab dalam melindungi masyarakat dan cara hidupnya, serta melindungi wilayahnya (Jackson dan Sorensen, 2009: 89).

Morgenthau yang beranggapan bahwa kepentingan nasional setiap negara pada akhirnya bertujuan untuk mencapai suatu kekuasaan, artinya negara tidak ingin ada campur tangan dari negara lainnya. Menurutnya, terdapat dua hal yang menjadi kunci utama dari kepentingan nasional, yakni power (kekuasaan) dan keinginan. Adapun persaingan antara China dan Australia dalam melebarkan pengaruhnya dikawasan, tidak lepas dari kepentingan nasional masing-masing negara, baik kepentingan ekonomi, militer maupun diplomatik.

\section{Pembahasan}

\subsection{Peran Australia di Pasifik}

Pada dasarnya Australia merupakan negara adikuasa di Pasifik, dimana sangat penting baginya untuk memainkan perannya dikawasan tersebut. Sebagai negara yang memiliki perkembangan ekonomi yang signifikan, kualitas yang tinggi dalam berbagai bidang seperti, pendidikan dan lembaga pelatihannya, memiliki infrastruktur yang maju serta merupakan salah satu negara dengan penggunaan teknologi yang termasuk tertinggi di dunia. Australia telah menjadi negara maju terkemuka di wilayah Pasifik Selatan pada saat Inggris memberikan kemerdekaan kepada bekas jajahannya tersebut dan menarik diri pada 1970-an (Brown 2012). Sebagai pemain utama Australia telah lama tecatat sebagai mitra dagang serta pendonor bantuan terbesar di Pasifik.

Sebagai aktor tradisional yang telah melebarkan pengaruhnya dikawasan, Australia tercatat telah banyak memberikan bantuan terhadap negara-negara dikawasan Pasifik agar menjadi negara yang mandiri dalam hal perekonomian, keamanan Negara, filsafat pemerintahan dan sebagainya. Kemudian Australia telah mendukung berbagai upaya pembangunan berkelanjutan di negara-negara Kepulauan Pasifik baik itu melalui program kerjasama bilateral ataupun regional. Australia juga telah melakukan berbagai bentuk kerjasama dengan negara-negara kepulauan Pasifik baik secara bilateral maupun regional untuk lebih mengembangkan hukum dan ketertiban mereka, menjaga keamanan perbatasan, serta dalam hal manajemen ekonomi (Brown 2012). Tujuan Australia yakni agar Pasifik aman secara strategis, memiliki ekonomi yang stabil dan berdaulat secara politis. Pada saat ini Australia telah berinvestasi dalam sektor pembangunan berkelanjutan lebih besar dari sebelumnya, kemudian Australia tercatat sebagai mitra pembangunan bilateral terbesar di wilayah Pasifik. bantuan pembangunan Australia fokus kepada pembangunan ekonomi berkelanjutan serta meningkatkan kerja sama keamanan.

Dalam konteks keamanan, Australia telah banyak terlibat dalam menciptakan keamanan regional khususnya di Pasifik Selatan, meskipun hal ini tentu tak lepas pula dari kepentingan nasional Australia sendiri. Selain karena banyaknya warga negara Australia di wilayah tersebut seperti di Papua Nugini, hal lain yakni faktor geografisnya yang apabila negara Kepulauan Pasifik menghadapi krisis maka Australia sebagai negara tetangga juga tentu akan mendapat banyak dampak dan kerugian. Seperti apabila terjadi konflik atau krisis yang melanda akibatnya dapat meningkatkan arus pengungsi dengan jumlah besar ke Australia. Kemudian karena masih tingginya ancaman kejahatan transnasional seperti terorisme, perdagangan narkoba dan manusia, serta tingginya angka imigran gelap yang dapat 
melewati wilayah pasifik menuju Australia. Hal inilah yang kemudian membuat Australia berupaya untuk selalu menjaga keamanan regional dikawasan.

Bentuk kerjasama yang dibangun oleh Australia sebagai upaya pencapaian kepentingan keamanan regional dan integrasinya di kawasan Pasifik Selatan adalah melalui keterlibatannya dalam organisasi SPF (South Pacific Forum), yang kini dikenal dengan PIF (Pasific Island Forum) yang merupakan organisasi utama di kawasan Pasifik dengan negara anggota berjumlah 16 negara yakni Australia, Cook Islands, Federated States of Micronesia, Kiribati, Marshall Islands, Nauru, Niue, Palau, Samoa, Selandia Baru, Solomon Islands, Tonga, Tuvalu, Fiji, Papua Nugini dan Vanuatu. PIF merupakan organisasi politik yang membahas mengenai isu-isu umum serta masalah-masalah yang dihadapi oleh negara anggota. Serta adanya kerjasama dengan PPBP (Pacific Patrol Boat Program) yang merupakan bantuan Program peningkatan kemampuan kepolisian sebagai bentuk bantuan terhadap penguatan sektor nasional negara-negara di kawasan Pasifik Selatan. Kerjasama tersebut dilakukan sebagai upaya Australia dalam melindungi wilayah-wilayah yang dianggap strategis. Australia tetap menjadi mitra keamanan utama bagi banyak negara di kawasan ini dan memikul banyak tanggung jawab keamanan untuk Pasifik Selatan.

Dalam upaya perdamaian di Kepulauan Solomon, Australia juga beperan dengan membentuk sebuah misi bantuan yang dikenal dengan RAMSI (Regional Asistance Mission to Solomon Island) melalui RAMSI Australia telah melakukan intervensi kemanusiaan di kepulauan Solomon. Konflik yang terjadi di Kepulauan Solomon membuat negara tersebut menjadi tidak stabil, China kemudian hadir bermaksud untuk memberikan bantuan ekonomi terhadap Kepulauan Solomon dengan maksud memuluskan kebijakan 'One China Policy' di Kepulauan Solomon. Namun, upaya China tersebut tidak berjalan mulus dan semakin memperburuk keadaan dengan meningkatnya jumlah korupsi yang terjadi yang justru mebuat terjadinya perpecahan antar penduduk. Lemahnya perekonomian negara-negara Pasifik Selatan membuat negara-negara besar memanfaatkannya untuk kepentingan persaingan politik dan pengaruh. Lebih lanjut, bantuan ekonomi yang diberikan China memang tidak berjalan mulus, terlebih justru membuat Kepulauan Solomon berpotensi terkena jebakan hutang (Febriani, 2018).

Selain upaya Pemerintah Australia dalam pembangunan Internasional dan mendukung terciptanya keamanan di Pasifik, dalam bidang pendidikan Australia juga mendukung sistem pendidikan di Vanuatu dengan membantu anak-anak di Vanuatu agar mereka dapat mencapai potensinya serta dapat berkontribusi untuk masa depan yang cerah bagi negaranya. Adapun Pemerintah Australia akan mengkaji kembali terkait bantuan luar negerinya dalam kebijakan baru Pemerintah Australia yakni upaya mempertahankan anggaran pembangunan yang ditargetkan sebesar \$ 4 miliar per tahun. Dalam Buku Putih Kebijakan Luar Negeri, kebijakan Australia dipastikan akan sejalan dengan prioritas dari strategis Pemerintah yang meliputi program-program pembangunan serta mendukung pembangunan internasional. Dalam kebijakan tersebut mendorong pemerintah Australia untuk meningkatkan pembangunan internasional, dimana menggambarkan bahwa Pemerintah Australia menekankan dalam hal kemitraan strategis dan ekonomi di Indo-Pasifik serta dalam upaya mendukung terwujudnya keamanan, stabilitas, kemakmuran negara, dan ketahanan di Indo-Pasifik. (Australia Government, 2019)

Menurut data yang tercatat dari Australia Government total bantuan pembangunan resmi Australia ke negara-negara Pasifik pada 2019-2020 menunjukan bahwa Papua Nugini sebagai penerima bantuan terbesar dari Australia yaitu sebesar $\$ 607.5 \mathrm{~m}$, kemudian diperingkat kedua yaitu Kepulauan Solomon dengan bantuan sebesar \$174.4m dengan total bantuan pembangunan kepada Pasifik sebesar $\$ 1.4$ billion. Sedangkan prioritas utama investasi Australia yakni dalam sektor pemerintahan sebesar $26.0 \%$, infrastruktur dan 
perdagangan sebesar 23.6\%, Pendidikan 16.6\%, kesehatan $15.3 \%$. Ketahanan 9.7\%, Pertanian, perikanan dan air 6.4\% (Australia Government, 2019).

Gambar 1. Bantuan Pembangunan Australia di Pasifik

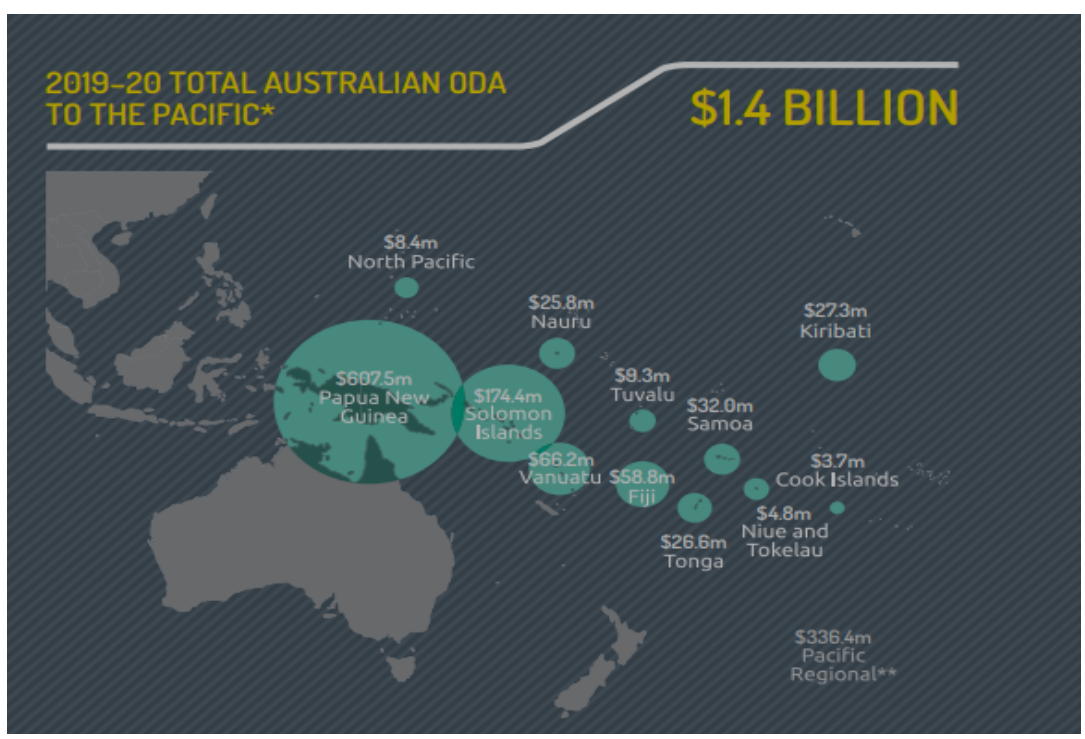

Sumber: Australia Government

Sebagai tetangga dekat, Australia memiliki hubungan bilateral yang harmonis dan kuat dengan negara-negara di Pasifik, seperti dengan Papua Nugini Australia melakukan kerjasama dalam berbagai bidang, diantaranya adalah kerjasama dalam bidang ekonomi, bidang keamanan dan pembangunan. Australia juga menjadi mitra pembangunan di Kepulauan Solomon, yang merupakan salah satu negara termiskin diwilayah ini, dengan Produk Domestik Bruto (PDB) per kapita sebesar USD2.270. tujuan Australia di Kepulauan Solomon yaitu berfokus untuk mendukung stabilitas, pertumbuhan ekonomi serta meningkatkan pembangunan sumber daya manusia. Selain di papua Nugini dan Kepulauan Solomon, Australia juga menjalin hubungan baik dengan negara-negara Pasifik lainnya.

Adanya peningkatan investasi infrastruktur serta proyek-proyek bantuan yang diberikan China dikawasan Pasifik, membuat para pemain tradisional merasa khawatir dengan pengaruh China yang semakin kuat dikawasan tersebut. China telah banyak mengeluarkan dana besar dalam berbagai proyek pembangunan infrastruktur dan transportasi. Secara umum pemerintah Australia mendukung kontribusi China terhadap pembangunan ekonomi di kawasan Pasifik. Namun, terdapat pula kekhawatiran akan China sebagai ancaman. Berbagai upaya dilakukan oleh Pemerintah Australia guna menangkal pengaruh China dikawasan. Di kepulauan Solomon dan Papua Nugini, Australia mendanai proyek kabel bawah laut sepanjang $730 \mathrm{~km}$. Australia menjadi mitra Papua Nugini dan Solomon dalam proyek ini karena tidak ingin China yang terlibat dalam membangun proyek tersebut dan merasa khawatir apabila China semakin melebarkan pengaruhnya dengan melancarkan soft diplomacy nya di Pasifik. Sistem Kabel Laut ini merupakan wujud Australia untuk meningkatkan infrastruktur komunikasi dan pengembangan ekonomi yang signifikan di wilayah Pasifik.

Untuk meningkatkan keterlibatannya di Pasifik Pada 2019-2020 Pemerintah Australia akan menyalurkan dana dalam jumlah besar ke negara-negara kepulauan Pasifik, untuk pembangunan berkelanjutan di Pasifik, Australia akan melakukan berbagai investasi baru untuk membangun infrastruktur, proyek-proyek telekomunikasi, energi, transportasi dan air. Bantuan dilakukan dengan menggunakan dana hibah dan berupa pinjaman non lunak. Langkah yang diambil oleh pemerintah Australia ini dinilai untuk menangkal pengaruh China 
di Pasifik dengan menekankan keterlibatannya kepada negara-negara Pasifik. Kemudian Pemerintah Australia juga akan memangkas bantuan luar negerinya terhadap negara-negara di Asia Tenggara termasuk Indonesia, hal itu dilakukan untuk memfokuskan bantuan luar negerinya terhadap negara-negara di Pasifik dengan menjadikannya sebagai salah satu prioritas dalam kebijakan luar negerinya. Australia juga akan meningkatkan hubungan pertahanan dan keamanannya dengan pulau-pulau di Pasifik melalui latihan militer bersama serta berjanji akan meningkatkan kemampuan keamanan dunia maya. langkah yang diambil oleh pemerintah Australia ini adalah dinilai untuk menangkal pengaruh China di Pasifik.

\subsection{Peningkatan peran China di Kawasan Pasifik}

Meskipun kecil dalam luas geografis kawasan ini tetap menjadi perhatian China karena jumlah penduduk dan potensi ekonominya. Jika ditinjau kembali dalam sejarahnya China bukan sepenuhnya merupakan pemain baru dikawasan ini. Sejak akhir abad kesembilan Imigran China telah menginjakkan kaki di Pasifik Selatan. Crocombe (2007) juga menyatakan bahwa orang-orang Austronesians yang merupakan asal mula bangsa China telah menginjakkan kakinya di Pasifik sekitar 10.000 tahun silam, yang kemudian mereka bermigrasi ke berbagai tempat dan menyebar keberbagai tempat dikawasan ini. Setidaknya terdapat sejumlah keturunan China yang tinggal di wilayah Melanesia yaitu, Kepulauan Solomon, Vanuatu, dan New Caledonia, serta Micronesia yaitu, Kiribati, Nauru, Tonga, Cook Islands, yang sebagian merupakan pedagang, buruh, pendatang, dan keturunan China yang tidak lagi memiliki keterikatan dengan tanah leluhurnya (Willmott 2007). Meskipun demikian China juga bukan merupakan pemain tradisional di kawasan ini.

Pasca Perang Dingin, China meningkatkan perhatiannya di Pasifik bukan karena vacuum of power, akan tetapi karena meningkatnya perhatian dan kehadiran kembali negaranegara Barat seperti Australia, New Zealand, Prancis, Uni Eropa dan Jepang (Wesley-Smith 2007). Sebagai negara adikuasa yang tumbuh dengan kepentingan strategis China telah banyak menjalin hubungan bilateral dengan negara-negara Pasifik seperti Cook Islands, Fiji, Niue, Papua Nugini, Samoa, Tonga dan Vanuatu. Guna memperkuat pengaruhnya China telah memperluas bantuan luar negerinya ke negara-negara di Pasifik, China tercatat sebagai negara pendonor dengan jumlah bantuan yang cukup besar. Ditandai dengan investasi serta berbagai bantuan yang diberikan seperti bantuan pendanaan untuk membangun infrastruktur yang dibutuhkan oleh negara-negara tersebut. Investasi dan bantuan dalam jumlah besar yang diberikan membuat China disambut baik oleh para pemimpin negara-negara Pasifik yang notabene-nya merupakan wilayah yang terdiri dari banyak negara berkembang dengan ratarata penghasilan nasional yang rendah. Kemudian diperkuat dengan adanya timbal balik yaitu kunjungan yang dilakukan oleh para pemimpin Pasifik Selatan ke China.

Selain berupaya untuk terus memperkuat hubungan baik dengan negara-negara di Pasifik, guna memperkuat keterlibatannya di kawasan Pasifik, China berperan sebagai peninjau dalam forum PIF (Pacific Island Forum) serta aktif sebagai pengamat dalam MSG (Melanesian Spearhead Group), yang merupakan organisasi yang terdiri dari negara-negara ras Melanesia dengan memberikan berbagai bantuan seperti bantuan infrastruktur. Dalam hal ini China lebih banyak terlibat dalam MSG karena tidak ada keterlibatan dari pemain tradisional didalam MSG (Brady 2015).

Dalam Forum Kerjasama Ekonomi dan Pembangunan Negara-Negara Pulau ChinaPasifik pada tahun 2006, China mengatakan akan meningkatkan jumlah pendanaannya dengan negara-negara yang memiliki hubungan bilateral dengannya. Upaya tersebut dilakukan China untuk meningkatkan pengaruhnya dikawasan (Brant 2015). Dalam tingkat regional, China tercatat sebagai pendonor yang sangat signifikan yang setara dengan para pemain tradisional dikawasan itu. Akan tetapi jika dilihat, Australia masih mendominasi sebagai pendonor 
terbesar dalam kawasan ini. Meskipun masih mendominasi, Australia tetap merasa khawatir akan pengaruh China yang yang sangat signifikan dikawasan Pasiifk.

Menurut data yang tercatat di lowy institute China telah mengadakan dua kali pertemuan regional untuk memperkuat pembangunan ekonomi serta keterlibatan diplomatik dengan wilayah tersebut. China berupaya untuk memberikan dukungan kepada organisasi regional utama dikawasan yakni Sekretariat Forum Kepulauan Pasifik. Seperti bantuanbantuan dalam program bilateral serta memberikan dukungan untuk organisasi regional. Bukan hanya investasi dalam bidang infrastruktur, China juga memberikan sejumlah beasiswa untuk para pelajar di kepulauan Pasifik serta pelatihan sumber daya manusia bagi pejabat pemerintah. Hal ini membuat China tercatat sebagai pendonor terbesar dalam beberapa negara dan telah menyaingi para pemain tradisional seperti Selandia Baru. Untuk memperluas BRI China berupaya untuk menjalin kerja sama dengan negara-negara kawasan dengan memberikan berbagai bantuan ekonomi serta pinjaman lunak jangka panjang, yang dapat dilihat dengan adanya bangunan pelabuhan di Pulau Penhryn di Cook dan lain sebagainya. Kemudian Tonga mendapat keringanan dalam pembayaran hutangnya (Ellis \& Devonshire, 2019).

Di Fiji, China merupakan pendonor bilateral terbesar dinegaranya, dimana hubungan kedua negara tersebut telah terjalin lama dan kuat pasca kudeta pada 2006, kemudian juga Papua Nugini yang mengklaim bahwa China merupakan pendonor utama di negaranya. Menurut akumulasi data dari 2006-2016 mencatat bahwa China telah memberikan total bantuan kepada wilayah Pasifik sebesar \$ 1.781,2 juta, dengan bantuan terbesar kepada Papua Nugini.

\section{Gambar 2. Bantuan China di Pasifik}

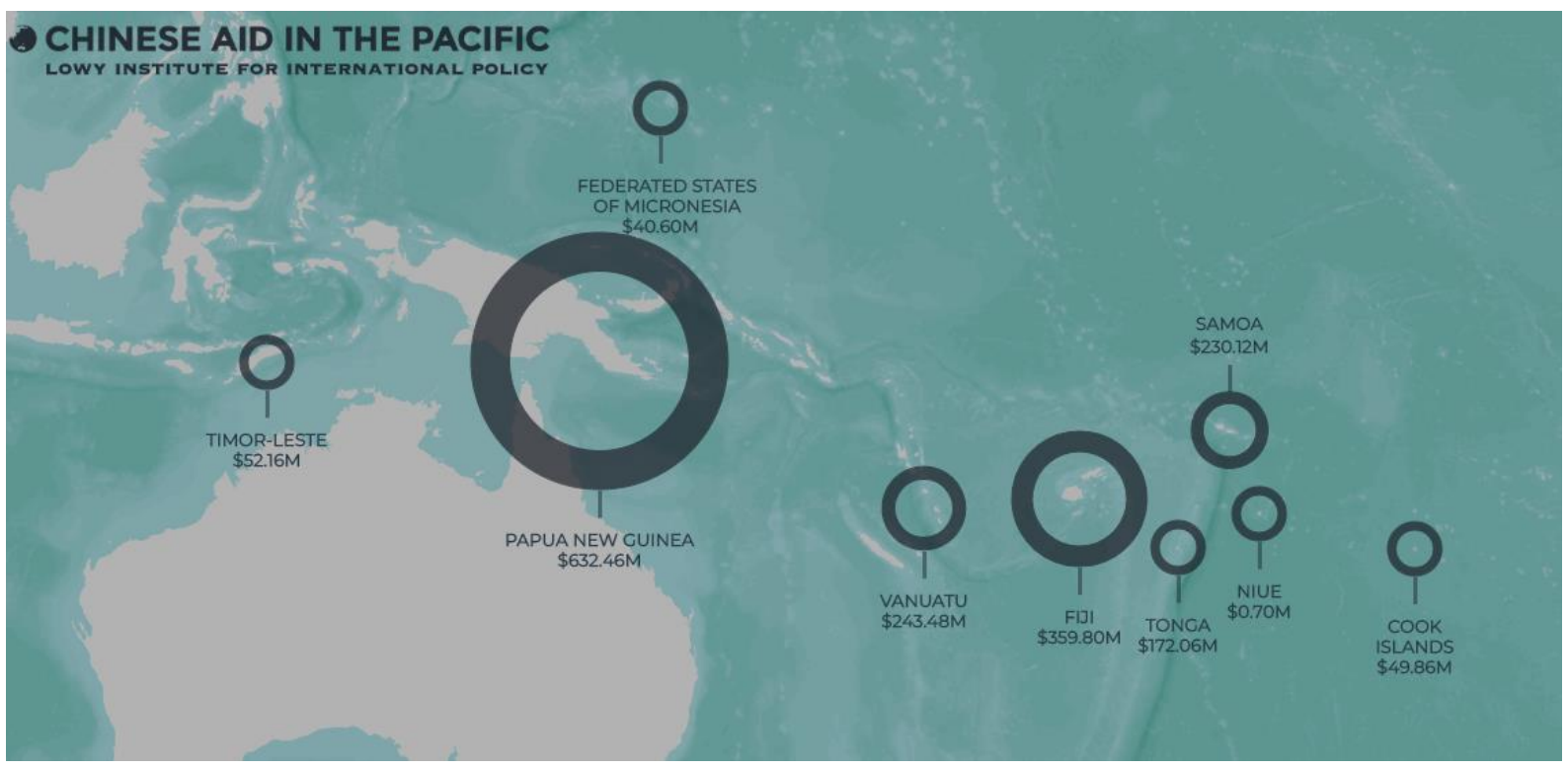

Sumber: Lowy Institute (akumulasi dari 2006 hingga Juni 2016)

Pada gambar diatas menunjukan bahwa Papua Nugini merupakan negara dengan penerima bantuan luar negeri terbesar dari China. China telah lama menjalin hubungan diplomatik dengan Papua Nugini sejak tahun 1976. Selain memberikan program bantuan luar negerinya, China juga banyak berinvestasi yang melibatkan perusahaan-perusahaan milik negara. Perusahaan-perusahaan China juga telah mendapatkan kontrak Pemerintah Papua Nugini dan Bank Pembangunan Asia, khususnya di sektor infrastruktur. Sejak 2006, hampir 
80 persen total bantuan yang diberikan China merupakan pinjaman dengan syarat lunak, tingginya bantuan yang diberikan China juga akhirnya membuat para penerima sumbangan mulai khawatir akan meningkatnya hutang negara mereka terhadap China. Seperti di Papua Nugini, China harus memperpanjang penawaran pinjaman lunaknya pada tahun 2006 akibat keterlambatan dari pihak Papua Nugini (Brant, 2015).

Investasi China cenderung kedalam proyek-proyek infrastruktur dalam skala besar. Berbeda dengan Australia sebagai aktor tradisional dikawasan telah banyak berinvestasi dalam bidang pemerintahan, kesehatan, pendidikan dan sebagainya. Menurut data dari Lowy Institute dalam investasi Australia dan Cina menunjukkan bahwa proyek utama Australia merupakan non-infrastruktur. Berbeda dengan China yang cenderung lebih banyak mengeluarkan pengeluarannya pada proyek infrastruktur. Seperti di Papua Nugini, Cina menyelesaikan peningkatan jalan pada tahun 2017. Sedangkan Australia telah menghabiskan senilai \$ 219 juta dalam bidang pendidikan kesehatan dengan memberikan obat-obatan penting seperti vaksin.

Kemudian upaya yang dilakukan China dalam bidang kerjasama militer China bersama Vanuatu, yang apabila kerja sama militer tersebut berhasil dilaksanakan, maka akan terdapat pangkalan militer yang berjarak hanya sekitar 2000 kilometer dari lepas pantai negara Australia (Wroe, 2018). Hal ini membuat Menteri Luar Negeri Australia Julie Bishop bersama pangeran Charles merespon dengan mengunjungi Vanuatu. Kunjungan tersebut yakni sebagi upaya Australia menunjukkan manfaat dari komitmen Persemakmuran terhadap Vanuatu serta upaya untuk menekan pengaruh China yang semakin melebar dikawasan. Sebab sekecil apapun peluang pendirian pangkalan militer China di Vanuatu, hal tersebut tentu akan sangat mempengaruhi kebijakan pertahanan Australia bahkan hingga beberapa dekade kedepan (Chibarirwe, 2018).

\subsection{Kepentingan China di Kepulauan Pasifik}

Dibeberapa negara China merupakan pemberi pinjaman bilateral yang cukup signifikan dikawasan ini, misalnya, Tonga yang merupakan negara di mana pinjaman China mendominasi. Dengan meningkatnya jumlah bantuan serta investasi dari negara raksasa ekonomi ini menimbulkan banyak pertanyaan apa yang menjadi kepentingan China di Kawasan ini. Dalam sebuah laporan Oxford analytic pada 2019, terdapat empat tujuan China dalam upaya memperluas jangkauannya ke Pasifik Selatan. Pertama, yakni untuk kepentingan memperluas batas luas keamanan China terhadap wilayah Pasifik. Kedua, yakni untuk tujuan diplomatik, dimana telah lama terjadi persaingan antara China dan Taiwan dalam perebutan pengaruh di Pasifik guna memperebutkan pengakuan diplomatik, di mana terdapat empat negara yang masih memiliki hubungan diplomatik dengan Taiwan di kepulauan Pasifik, yaitu Palau, Nauru, Tuvalu, dan Kepulauan Marshall. Sebelumnya Kepulauan Solomon dan Kiribati memiliki hubungan diplomatik dengan Taiwan, namun pada September 2019 lalu, setelah 36 tahun menjalin hubungan diplomatik dengan Taiwan, Kepulauan Solomon memutuskan untuk meninggalkan Taiwan dengan pengalihan hubungan diplomatik terhadap China, yang kemudian juga diikuti oleh Kiribati. Ketiga, yaitu alasan kekayaan sumber daya alam yang dimiliki oleh Pasifik seperti ikan dan kayu, tercatat bahwa China telah berinvestasi dalam jumlah besar yaitu sekitar \$30 miliar dan menjadi mitra dagang nomor satu dibeberapa negara dan disebagian besar pulau. Keempat, sebagai upaya untuk menarik negara-negara Pasifik Selatan ke Belt Road Initiative China dengan cara menjual infrastruktur kepada negara-negara tersebut, terlebih untuk fasilitas pelabuhan, hal ini upaya memberi manfaat bagi perdagangan China dan sebagai penyebaran jangka panjang angkatan lautnya (Manthrope 2019). 
Negara di kepulauan Pasifik memang dikenal kaya akan sumber daya seperti kayu, mineral dan ikan. Hal inilah yang juga menjadi salah satu faktor China tertarik untuk memberikan bantuan dan berinvestasi dengan jumlah besar di kepulauan Pasifik. Seperti di Papua Nugini China telah berinvestasi serta banyak membantu dalam bidang infrastrukturnya, dimana Papua Nugini dibandingkan dengan negara lainnya merupakan negara yang banyak memiliki emas, tambang nikel, gas alam cair dan hutan kayu. Namun, bukan hanya bantuan China yang mendominasi di Papua Nugini, akan tetapi Australia juga tercatat sebagai pemberi bantuan luar negeri terbesar kepada negara ini.

Kemudian adanya persaingan diplomatik antara China dengan Taiwan, sebagai negara yang diklaim China sebagai wilayah kedaulatannya. Persaingan tersebut diwarnai dengan adanya pemberian berbagai bantuan serta investasi yang dilakukan oleh kedua negara itu, seperti bantuan keuangan yang diberikan dalam jumlah yang signifikan bagi negara-negara Pasifik. Tujuan persaingan antara China-Taiwan tak lain untuk memperebutkan pengakuan diplomatik dari negara-negara di Pasifik, disebut sebagai "chequebook diplomacy". Diketahui bahwa kini Taiwan memiliki hubungan diplomatik dengan empat negara di Kepulauan Pasifik, diantaranya yaitu Kepulauan Marshall, Nauru, Palau dan Tuvalu, sementara China memiliki perwakilan diplomatik di Papua New Guinea, Fiji, Samoa, Vanuatu, Kiribati, Tonga dan negar federasi Micronesia, serta mendapatkan dukungan dari Cook Islands, Niue, serta Kiribati dan Kepulauan Solomon yang belum lama pada 2019 telah megalihkan pengakuan diplomatiknya dari Taiwan ke China. Saat ini, negara di Pasifik Selatan yang memiliki hubungan diplomatik dengan Taiwan berkurang menjadi empat karena Kepulauan Solomon yang diikuti oleh Kiribati telah mengalihkan hubungan diplomatiknya dengan Taiwan (Zhang 2019)

Dalam laporan Lowy Institute, tercatat bahwa investasi Taiwan di Pasifik Selatan menghabiskan \$215,87 juta. Akibat persaingan diplomatik antara China dan Taiwan ini seringkali membuat terjadinya ketidakstabilan politik di kawasan tersebut (Brady, 2015). Seperti kerusuhan yang terjadi di Tonga, Kepuluan Solomon dan Fiji, merupakan konsekuensi akibat persaingan antara China dan Taiwan. Persaingan diplomatik itu meningkatkan destabilitas di kawasan dan membuat perpolitikan menjadi lebih korup dan violent. Dampak buruknya dari persaingan ini dapat dilihat dari memburuknya hubungan yang terjadi antar etnis di provinsi Guadalcanal dan Malaita di Kepulauan Solomon (Henderson 2001).

Jika dilihat secara geografis, China juga mempunyai kepentingan yang tinggi terhadap Pasifik untuk menjaga keamanan maritimnya, sehubungan dengan lokasi geografis Pasifik yang luas dan dikelilingi oleh negara-negara penting di sekitar Samudra Pasifik. Ambisi China terhadap maritimnya ditunjukan dalam sebuah buku Putih Kelautan China yang berjudul China's Ocean Development Report (2012). Pasifik Selatan dapat menjadi target China bagi ekspansi maritim China. Untuk itu China memiliki kepentingan untuk menjalin hubungan yang kooperatif dengan negara-negara di Pasifik, khususnya dalam sektor keamanan perdagangan yang melewati jalur laut di Pasifik. Kemudian, berhubungan dengan zona ekonomi eksklusif juga menjadi kepentingan China terhadap akses maritim di pelabuhan negara-negara tersebut, dan juga memberikan program-program bantuan militer (Wallis 2012). Ekspansi maritime yang dilakukan China di Pasifik sebagai perwujudan dari strategi "Second Island Chain" yang merupakan manuver global China untuk membangun blue navy project. Strategi Second Island Chain merupakan kelanjutan dari "First Island Chain", yang mana secara geografis meliputi kepulauan di sekitar Jepang, Taiwan dan Laut China Selatan. Dengan demikian, terlihat bahwa kepentingan strategi China di Pasifik Selatan juga berdimensi militer. 


\section{Kesimpulan}

Peningkatan peran China di kawasan Pasifik ditandai dengan investasi serta berbagai bantuan luar negeri dalam jumlah besar yang diberikan oleh China terhadap wilayah ini. Hal ini mengkhawatirkan dan dianggap sebagai ancaman dari aktor tradisional dikawasan seperti Australia, Amerika Serikat dan Selandia Baru. Dengan adanya investasi serta proyek-proyek bantuan pembangunan, Australia dan China berusaha saling berlomba-lomba untuk menciptakan pengaruh mereka di negara-negara Pasifik. Untuk menangkal pengaruh China di Pasifik pemerintah Australia merespon dengan akan mengkaji kembali bantuan luar negerinya dengan memfokuskan pemberian bantuan ke negara-negara Pasifik dengan total anggaran \$ 4 miliar per tahun, kebijakan Australia ini meliputi program-program pembangunan serta mendukung pembangunan internasional. Dalam kebijakan ini menggambarkan bahwa Pemerintah Australia menekankan dalam hal kemitraan strategis dan ekonomi di Indo-Pasifik serta dalam upaya mendukung terciptanya keamanan, stabilitas, kemakmuran, dan ketahanan di Indo-Pasifik

Untuk meningkatkan keterlibatannya di Pasifik Pada 2019-2020 Pemerintah Australia akan menyalurkan dana untuk pembangunan berkelanjutan di Pasifik, Australia akan melakukan berbagai investasi baru untuk membangun infrastruktur, proyek-proyek telekomunikasi, energi, transportasi dan air. Bantuan dilakukan dengan menggunakan dana hibah dan berupa pinjaman non lunak. Langkah yang diambil oleh pemerintah Australia ini dinilai untuk menangkal pengaruh China di Pasifik dengan menekankan keterlibatannya kepada negara-negara Pasifik. Australia juga akan meningkatkan hubungan pertahanan dan keamanannya dengan pulau-pulau di Pasifik melalui latihan militer bersama serta berjanji akan meningkatkan kemampuan keamanan dunia maya. langkah yang diambil oleh pemerintah Australia ini adalah dinilai untuk menangkal pengaruh China di Pasifik. 


\section{DAFTAR PUSTAKA}

\section{Buku}

Brown, Peter. 2012. "Australian Influence in the South Pacific." ADF Journal 189 (December): 66-78.

Allan, Gyngell \& Wesley, Michael. 2003. Making Australian Foreign Policy. New York: Cambridge Univesrsity Press.

Leppman, Elizabeth J. Australia and the Pacific. Philadelphia. Chelsea House Publisher. 2006.

\section{Jurnal}

Bustelo, Pablo. 2005. "China's Emergence: Threat or 'Peaceful Rise'?" Ari 135: 1-6. http://www.realinstitutoelcano.org/analisis/850/bustelo850.pdf.

Shie, Tamara Renee. 2010. "Rising Chinese Influence in the South Pacific: Beijing'S Island Fever" 47 (2): 137-61. https://doi.org/10.1142/9789814304399_0006.

Henderson, John. 2001. "China, Taiwan and the Changing Strategic Significance of Oceania". Diakses pada 21 Oktober 2019. doi:10.1.1.476.1675.

Febriani, W. 2018. "Kepentingan Australia dalam intervensi di kepulauan Solomon melalui Regional Asistance Mission to Solomon Island (RAMSI)". Jurnal Fisip HI Unair, 1517.

Putri, Adinda Normala. 2019. "Persaingan Pengaruh di Pasifik Selatan: Pengalihan Dukungan Diplomati Kepulauan Solomon Dari Taiwan Ke Tiongkok". Jurnal Asia Pacific Studies Volume 3 Number 2 pp. 130-144 http://dx.doi.org/10.33541/japs.v3i2.1294

\section{Website}

Manthrope, Jonathan. 2019. "China targeting Pacific Isles for strategic bases." Asia Times, 8 Juni. Diakses pada 8 April 2020. https://www.asiatimes.com/2019/06/article/chinatargeting-pacific-isles-forstrategic-bases/.

Wroe, D. 2018. "China eyes Vanuatu military base in plan with global ramifications. Diakses pada 29 Mei 2020, from The Sydney Morning Herald" https://www.smh.com.au/politics/federal/china-eyes-vanuatumilitary-base-in-planwith-global-ramifications-20180409-p4z8j9.html

Chibarirwe, A. 2018. "Will China's Next Military Base Be in Vanuatu?" Diakses pada 29 Mei 2020, from the Trumphet: https://www.thetrumpet.com/17160-will-chinas-nextmilitary-base-be-invanuatu

Ellis, \& Devonshire, C. 2019. "Belt and road Pacific". Diakses pada 29 Mei 2020, from Silk Road Briefing: https://www.silkroadbriefing.com/news/2019/05/23/chinas-beltroadinitiative-pacific-islands/

Brant, Philippa. 2015. "The Geopolitics of Chinese Aid." Lowy Institute, diakses pada 8 April 2020. https://www.lowyinstitute.org/publications/geopolitics-chinese-aid

Australia Government. 2019. Diakses pada 12 April 2020. https://www.dfat.gov.au/aid/newinternational-development-policy/Pages/default

Crocombe, Ron, 2007. The Fourth Wave: Chinese in the Pacific Islands in the Twenty-First Century.CSCSD Occasional Paper Number 1, May 2007

Wesley-Smith, Terence. 2007. China in Oceania: New Forces in Pacific Politics. Pacific Islands Policy. 
Willmott, Bill. 2007. The Chinese Communities in the Smaller Countries of the South Pacific: Kiribati, Nauru, Tonga, the Cook Islands. Christchurch: Macmillan Brown Centre for Pacific Studies University of Canterbury. 